\title{
Radiographic revelation of an unusual inflammatory odontogenic cysts of mandible
}

\author{
Vinuthna Marneni ${ }^{1}$, Shakuntala Soujanya. $\mathrm{V}^{2, *}$, Abhishek Reddy. $\mathbf{N}^{3}$ \\ Assistant Professor, Dept. of Oral Medicine \& Radiology, Meghna Institute of Dental Sciences, Mallaram, Telangana, India \\ *Corresponding Author: \\ Email: shakuntalasoujanya@gmail.com
}

\begin{abstract}
Inflammatory odontogenic cysts are group of lesions which has propensity to occur in any jaw, at the site of persisting odontogenic infection with radicular cysts and periodontal cysts as its common entity. However, most of them share a common treatment modalities like removal of pulpal or periodontal pathologies followed by surgical enucleation or marsupilization of the cysts where radiographic and histopathological evaluation plays a promising role not only in treatment planning but also to evaluate prognosis. Here, in these article we are presenting such an unusual occurrence of two adjacent inflammatory and nonspecific inflammatory odontogenic cysts.
\end{abstract}

Keywords: Inflammatory odontogenic cysts, Non-specific inflammatory odontogenic cysts, OPG, Adjacent occurrence, Enucleation, Endodontic treatment.

\section{Introduction}

The odontogenic inflammatory cysts are group of lesions that have multiple factors affecting its etiopathogenesis which mainly have a low virulent and long term proliferating endodontic, periodontal or pericoronal infections as main cause ${ }^{1}$ where the source of inflammation may be a necrotic pulp or periodontal disease. ${ }^{2}$ As they grow slowly from the remaining epithelial rest cells of Malaseez or a pre-existing periapical granulomas ${ }^{3}$ they often commonly occurs within the bone and very rarely occurs in extra osseous regions and due to this they are included in the differential diagnosis of benign lesions of the mandible. ${ }^{4}$ Although they appears to be benign, depending on size, they can become destructive causing major damage to both the jaws ${ }^{5}$ causing esthetic and functional disability to the patient.

\section{Case Report}

Here is a reported case of a $25 y$ rs female who complains of a swelling on left side of face near lower left back teeth region from 3 days which got aggravated on counter irritant application where an insight into the case has revealed a solitary swelling obliterating buccal vestibule w.r.t 35363738 extending anteroposteriorly from distal of 35 to distal of 38; mediolaterally from buccal gingiva to buccal vestibule; superoinferiorly from retromolar region to anterior buccal vestibule measuring size $6 \mathrm{~cm}_{x} 3 \mathrm{~cm}_{\mathrm{x}} 1 \mathrm{~cm}$ approximately with root stumps i.r.t 36. Hence considering history and clinical presentation, a provisional diagnosis of dentoalveolar abscess was given initially with a differential diagnosis of pericoronal abscess, odontogenic cysts and odontogenic tumors. On further investigations, an OPG has revealed an occurrence of two adjacent welldefined, unilocular radiolucencies with corticated borders, one involving root of 36 other involving root of retained deciduous root stump i.r.t 3435 and hence later a radiographic diagnosis of radicular cysts was given. However, further histopathological evaluation has revealed, an interrupted delicate 2-3 layered cystic epithelium with underlying connective tissue capsule consisting of delicate collagen bundles, fibroblasts, blood vessels, nerve bundles, focal to diffuse chronic inflammatory cell infiltrate, reactionary bone formation along with the evidence of cholesterol granuloma consisting of chiefly lymphocytes, plasma cells, giantcells and deposits of cholesterol crystals, extravasated RBC's, Haemosiderin pigment w.r.t pathology involoving 36 suggesting of inflammatory odontogenic cyst (Non-specific origin)

The later cyst involving retained deciduous root stumps i.r.t 34, 35 histopathologically has revealed nonkeratinized, edematous stratified squamous epithelium with inflammatory cell infiltrate within epithelium, arcading pattern in few areas enclosing engorged capillaries and the cystic capsule shows delicate parallel arranged collagen, blood vessels, diffuse dense chronic inflammatory cell infiltrate suggesting of the inflammatory odontogenic CYST.

Finally, the lesions are treated initially by the enucleation of the cysts, removal of the retained deciduous root stumps and endodontic treatment of the diseased teeth.

\section{Discussion}

The odontogenic inflammatory cysts are usually asymptomatic to appreciate clinically, but many times found as an incidental radiographic findings during routine radiographic investigations. ${ }^{6}$ They occur more commonly in the maxilla, but inflammatory cysts of residual type were found to be occurring most commonly in the posterior jaw segments of mandible. They share many of the clinical features as that of any benign lesions such as a pattern of slow, expansive and non-infiltrated growth. ${ }^{7}$ If the cyst reaches a size 20-35 $\mathrm{mm}$ in diameter, or in case of exacerbations, signs and symptoms appear, such as destruction of the outer 
cortical bone, toothache, hard, painless swelling, increased tooth mobility, sudden extrusion, light sensitivity, being possible mobility and displacement of adjacent dental elements also. ${ }^{8}$ These clinical manifestations often becomes aggressive once secondarily infected. Then coming to the sex predilection, it is most common in males, but in the case of radicular cyst it shows a higher prevalence in women. ${ }^{9}$

There is no perspective with respect to age predilection, but the occurrence of radicular cysts is most common in third and fourth decades of life with the rare prevalence of radicular cysts and residual cysts occuring in children. ${ }^{10}$

Then, the radiographic imaging plays an important role in diagnosing many of the odontogenic inflammatory cysts which include digital intraoral, panoramic, periapical, occlusal and teleradiography ${ }^{11}$ which not only helps us in assessing the etiological teeth involved but also helps us in visualizing the anatomical extensions of the pathology, which may include conventional CT, MRI, US and CBCT, etc., thus helping in making preoperative accurate and versatile diagnosis, facilitating the differentiation and planning, streamlining the treatment and follow-up of periapical lesions. ${ }^{12}$ The CBCT, besides indicating the presence of apical periodontitis, has proven efficient in diagnosis and differentiating granuloma and periapical cysts more efficinetly. ${ }^{13}$

The periapical cystic lesions are usually treated by conservative endodontic treatment procedures like periapical curettage, surgical treatment procedures like enucleation, marsupialization or fenestration and decompression. ${ }^{14}$ According to Silva et al. with these type of the cysts of the jaws, the treatment is purely surgical in nature where therapeutic enucleation, the marsupialization and decompression can be performed. ${ }^{15}$ However, the Domingues \& Gil et al. opinied that the odontogenic cysts, with the exception of inflammatory periapical cyst and lateral radicular cyst, they should be treated with surgical intervention. ${ }^{16}$

In lateral root and inflammatory periapical cysts, surgery is indicated only if the lesions do not regress after removal of intracanal odontogenic infection of the affected tooth, ${ }^{17}$ however in the case of residual cyst or paradental cyst, surgery is the only treatment opted..$^{18}$ In 1987 Neville et al. suggested that as all cysts, odontogenic and non-odontogenic tumors mimics the appearance of a residual periapical cyst, they should be surgically excised for the complete evaluation of the ignition source. ${ }^{19}$

\section{Conclusion}

Thus, the odontogenic inflammatory cysts of specific or non-specific origin must be treated as specific entity where proper radiographic and professional evaluation is needed as each cyst has its own surgical indications according to its type, size, shape, location, degree of expansion and involvement with the underlying structure, often considering the cystic contents, the general condition of the patient, where immediate or delayed removal of the cyst can be done with the conservation of the structure and vitality of teeth as well as the preserving the integrity of anatomical structures.

\section{Clinical Examination}

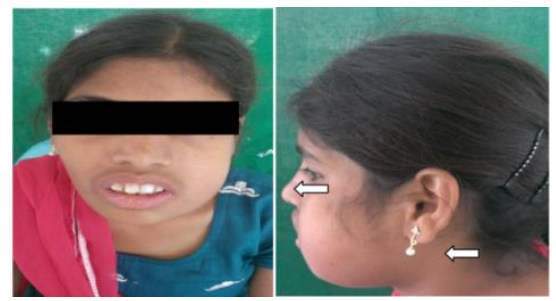

Fig. 1a:

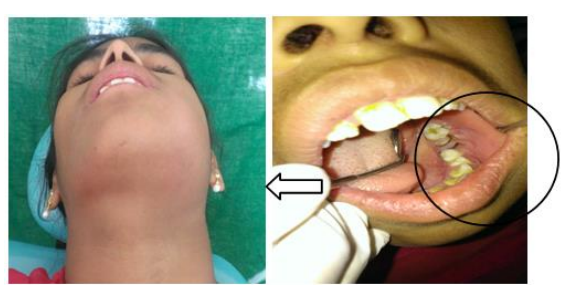

Fig. 1b:

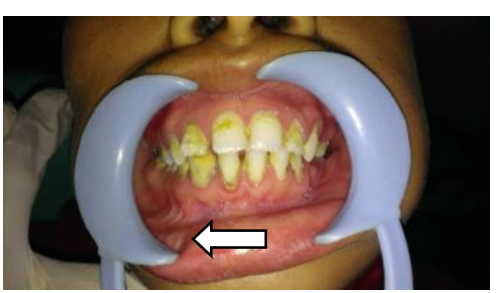

Fig. 1c:

Pre-op Radiographs

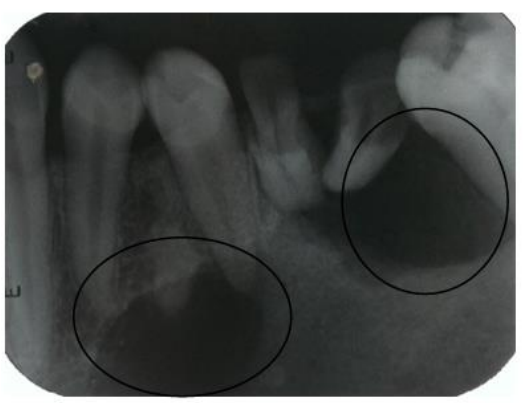

Fig. 2a: IOPA

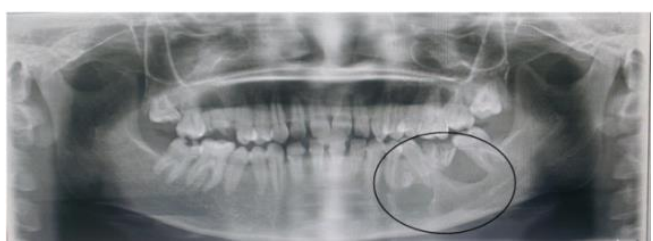

Fig. 2b: OPG 


\section{Enucleation of cyst}

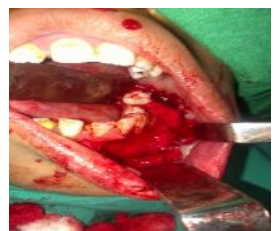

Fig. 3a:

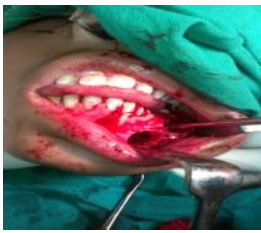

Fig. 3b:

\section{Histopathological Microphotographs}

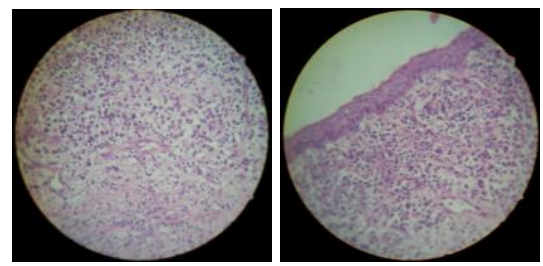

Fig. 4a: Odontogenic inflammatory cyst

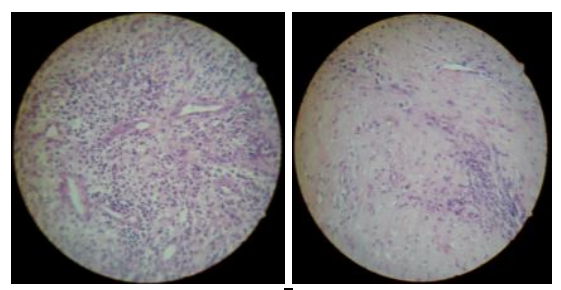

Fig. 4b: Non-specificinflammatory odontogenic cyst

\section{Post-op Clinical Evaluation}

Fig. 5:

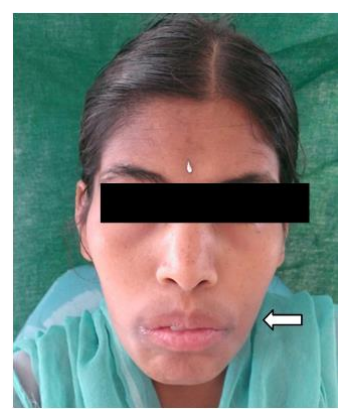

\section{Post-op OPG}

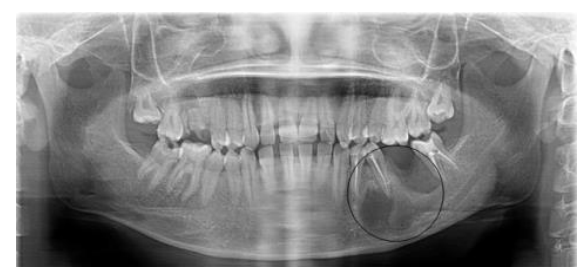

Fig. 6:

\section{References}

1. Simon EN, Merkx MA, Vuhahula E, Ngassapa D, Stoelinga PJ. A 4-year prospective study on epidemiology and clinicopathological presentation of odontogenic tumors in Tanzania. Oral Surg Oral Med Oral Pathol Oral Radiol Endod. 2005; 99:598-602.
2. Fernandes AM, Duarte EC, Pimenta FJ, Souza LN, Santos VR, Mesquita RA, et al. Odontogenic tumors: a study of 340 cases in a Brazilian population. J Oral Pathol Med. 2005;34:583-587.

3. Buchner A, Merrell PW, Carpenter WM. Relative frequency of central odontogenic tumors: a study of 1,088 cases from Northern California and comparison to studies from other parts of the world. J Oral Maxillofac Surg. 2006;64:1343-1352.

4. Elarbi M, El Gehani R, Subhashraj K, Orafi M. Orofacial tumors in Libyan children and adoles-cents. A descriptive study of 213 cases. Int J Pediatr Otorhinolaryngol. 2009;73:237-242.

5. Tay AB. A 5-year survey of oral biopsies in an oral sur gical unit in Singapore: 1993-1997. Ann Acad Med Singapore. 1999; 28:665-671.

6. Dhanuthai K, Banrai M, Limpanaputtajak S. A restropective study of paediatric oral lesions from Thailand. Int J Paediatr Dent. 2007;17:248-253.

7. Carlson RE. Odontogenic cysts and tumors. In: Miloro Michael., editor. Peterson's Principles of Oral and Maxillofacial Surgery. 2nd edn. London: BC Decker Inc; 2004. pp. 576-96.

8. Kreidler JF, Raubenheimer EJ, Van Heerden WF. A retrospective analysis of 367 cystic lesions of the jaw-the Ulm experience. J Craniomaxillofac Surg. 1993;21:33941.

9. Bataineh AB, Rawashdeh MA, Al Qudah MA. The prevalence of inflammatory and developmental odontogenic cysts in a Jordanian population. A clinicopathologic study. Quintessence Int. 2004;35(10):815-9.

10. Radden BG. Odontogenic cysts. A review and a clinicopathological study of 368 odontogenic cysts. Aust Dent J. 1973;18:218-25.

11. Rengaswamy V. Clinical statistics of odontogenic cysts in west Malaysia. Br J Surg. 1977-78;15:160-65.

12. Mosqueda TA, Irigoyen MF, Diaz MA, Torres MA. Odontogenic cysts. Analysis of 856 cases. Med Oral. 2002;7:89-96.

13. Ledesma-Montes C, Hernandez-Guerrero JC, GarcesOrtiz M. Clinicopathologic study of odontogenic cysts in a Mexican sample population. Arch Med Res. 2000;31:373-76.

14. Tay AB. A 5-year survey of oral biopsies in an oral surgical unit in Singapore: 1993-97. Ann Acad Med Singapore. 1999;28:665-71.

15. Tortorici S, Amodio E, Massenti M, Buzzanca ML, Burruano F, Vitale F. Prevalence and distribution of odontogenic cysts in Sicily: 1986-2005. J Oral Sci. 2008;50:15-8.

16. Abrahams JJ, Oliverio PJ. Odontogenic cysts: improved imaging with a dental CT software program. Am J Neuroradiol. 1993;14:367-74.

17. Bodner L, Woldenberg Y, Bar-Ziv J. Radiographic features of large cystic lesions of the jaws in children. Pediatr Radiol. 2003;33:3-6.

18. Hisatomi M, Asaumi J, Konouchi H, Shigehara H, Yangai Y, Kishi K. MR imaging of epithelial cysts of the oral and maxillofacial region. Eur J Radiol. 2003;48:17882.

19. Leorik-Pereira da Silva et al,.Epidemiologic study of odontogenic and non-odontogenic cysts in children and adolescents of a Brazilian population. Med Oral Patol Oral Cir Bucal 2018Jan, 23(1): e49-53. 